\title{
Characterization of Fe implanted yttria-stabilized zirconia by cyclic voltammetry
}

\author{
B.A. van Hassel and A.J. Burggraaf \\ Laboratory for Inorganic Chemistry, Materials Science and Catalysis, Department of Chemical Technology, University of Twente, \\ P.O. Box 217, 7500 AE Enschede, The Netherlands
}

Received 16 December 1990; accepted for publication 9 March 1992

\begin{abstract}
The technique of cyclic voltammetry has been applied to study reduction and oxidation phenomena which are observed at low oxygen partial pressures during steady state current-overpotential measurements of the $\mathrm{Au}, \mathrm{O}_{2}(\mathrm{~g}) / \mathrm{Fe}$ implanted yttria-stabilized zirconia interface. The redox potential $\left(E^{0}\right)$ of the observed redox couple is in close agreement with the thermodynamic potential of coexistent $\mathrm{Fe}_{2} \mathrm{O}_{3}$ and $\mathrm{Fe}_{3} \mathrm{O}_{4}$ phases. Hence in the forward sweep of the cyclic voltammogram, defined for negatively swept potential, part of the $\mathrm{Fe}^{3+}$ is reduced to $\mathrm{Fe}^{2+}$. The peak currents in the voltammogram result from a redox reaction which is rate limited by the diffusion of electrons or electron holes in the Fe implanted YSZ surface to the implanted Fe ions rather than by the diffusion of the $\mathrm{Fe}$ ions themselves.
\end{abstract}

\section{Introduction}

The implantation of a high dose of Fe in yttria-stabilized zirconia (YSZ) results in important changes of the electrochemical properties of the $\mathrm{Au}, \mathrm{O}_{2}(\mathrm{~g}) /$ YSZ interface [1,9]. An increase of the equilibrium exchange current density with a factor 10 to 50 is observed. Impedance measurements revealed an increase of the double layer capacitance with a factor of about 10-100, which suggests that the implanted $\mathrm{Fe}$ ions provide an alternative way for charge accumulation at the $\mathrm{Au}, \mathrm{O}_{2}(\mathrm{~g}) / \mathrm{YSZ}$ interface. Several reduction and oxidation phenomena in the currentoverpotential curve (occurring at low oxygen partial pressures $\left.\left(P_{\mathrm{O}_{2}}<10^{-3} \mathrm{~atm}\right)\right)$ are ascribed to the reduction and oxidation of iron oxides. In this study the technique of cyclic voltammetry is used to characterize the iron oxides in question.

\section{Experimental}

The preparation of the yttria-stabilized zirconia (YSZ) discs is discussed in detail elsewhere [2,9]. The ion implantation has been performed at room temperature in a vacuum of $4 \times 10^{-7}$ Torr. The YSZ discs were implanted perpendicular to the sample surface at a beam current density of $2 \mu \mathrm{A} \mathrm{cm}^{-2}$ using the isotope separator of the Laboratory for General Physics (LAN) of the State University of Groningen. $\mathrm{FeCl}_{2} \cdot 4 \mathrm{H}_{2} \mathrm{O}$ (Merck, p.a.) was used as feed material for the hot cathode ion source. In this paper the experiments were performed on YSZ discs, implanted with $15 \mathrm{keV}{ }^{56} \mathrm{Fe}$ up to a dose of $8 \times 10^{16}$ at. $\mathrm{cm}^{-2}$. After $\mathrm{Fe}$ implantation the YSZ disc showed a brown metallic colour. Upon oxidation in air at $400^{\circ} \mathrm{C}$ of this disc an orange colour was obtained. An area of $8 \mathrm{~mm}^{2}$ at the centre of the yttria-stabilized zirconia sample was protected against $\mathrm{Fe}$ implantation by an aluminum mask.

Annular working and counter electrodes were made by sputtering the surface with gold up to a thickness of $500 \mathrm{~nm}$. The edge and centre of the pellet were protected against gold deposition by an aluminum mask. The pellet was sandwiched between two annular gold foils with gold leads. The iron implanted disc was expected to exhibit electronic conduction. Hence the reference electrode was placed on the not implanted part of the sample in the centre of the annular working electrode in order to prevent possible electronic shortcircuiting with the working electrode. A schematic representation of the three ter- 
minal electrochemical cell is given in fig. 1 .

The cyclic voltammetric measurements have been performed with a Bank Pos 73 potentiostat. The current was passed between the working and the counter electrode while the potential being controlled between the working and the reference electrode. The potential was varied linearly with time with a sweep rate varying from 2 to $200 \mathrm{mV} / \mathrm{s}$. After data collection, the measured peak potentials were corrected for the uncompensated resistance between the working and reference electrode, which was determined by impedance spectroscopy. The potential scale was normalized with respect to $P_{\mathrm{O}_{2}}=1 \mathrm{~atm}$.

The measurements were performed in a nitrogen atmosphere in order to prevent the oxidation of the reduced $\mathrm{Fe}$ ions at the $\mathrm{Au}, \mathrm{N}_{2}(\mathrm{~g}) / \mathrm{Fe}$ implanted yttria-stabilized zirconia interface. The impurity oxy-
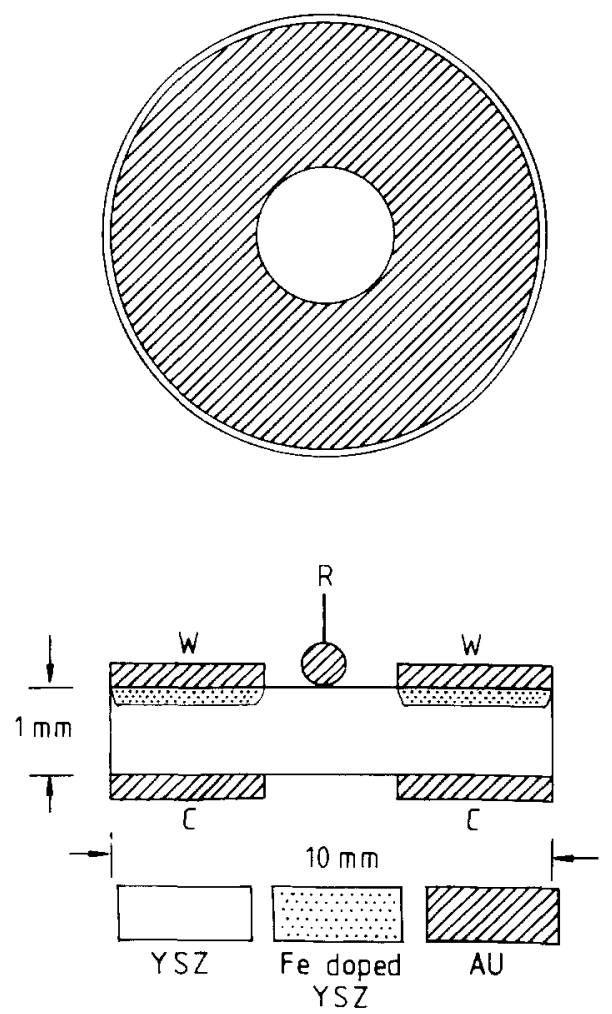

Fig. 1. Geometry of the three-electrode electrochemical cell. The working (W) and counter (C) electrode have an annular symmetry. The reference electrode $(R)$ is placed at the same side of the sample as the working electrode. The thickness of the Fe implanted layer is exaggerated. gen content in the nitrogen gas was measured to be $2 \times 10^{-6}$ atm using an YSZ oxygen sensor.

Sharp peaks in the cyclic voltammogram, which are indicative of a well defined redox process, were obtained in the temperature range of $750^{\circ} \mathrm{C}$ to $850^{\circ} \mathrm{C}$. At lower temperatures the oxidation and reduction peaks broadened considerably.

\section{Results and discussion}

\subsection{Surface composition}

YSZ was implanted with $15 \mathrm{keV}$ Fe ions up to a dose of $8 \times 10^{16} \mathrm{at}^{-2}$. A doped zone with a maximum iron concentration of 50 cat. $\%$ is created at the surface of the yttria-stabilized zirconia sample with a thickness of about $20 \mathrm{~nm}$. The implanted Fe ions proved to be present in the $\mathrm{Fe}^{3+}$ oxidation state after the oxidation treatment, as determined by XPS $[3,9]$. ISS experiments, [2,9] showed that the outermost surface layer with an estimated thickness of less than $2 \mathrm{~nm}$ consisted mainly of $\mathrm{Fe}_{2} \mathrm{O}_{3}$. A more detailed discussion about the thermal stability and microstructure of the implanted layer can be found in $[2,3,9]$.

\subsection{Cyclic voltammetry}

In a cyclic voltammetric experiment the electrode potential is swept linearly with a scan rate $v$, over a certain potential range with respect to a reference electrode. The resulting current can be monitored as a function of the time or as a function of the electrode potential. The latter method was employed in this study. The forward sweep is defined for negatively swept potentials, as indicated in fig. 2 , which shows cyclic voltammograms measured from the $\mathrm{Au}$, $\mathrm{N}_{2}(\mathrm{~g}) / \mathrm{Fe}$ implanted yttria-stabilized zirconia interface. The forward and reverse peaks are only observed on the Fe implanted sample and can therefore be related to the reduction and the oxidation of iron oxides. The measured parameters of interest are the peak currents and the positions of the peak potentials.

\subsubsection{Peak current}

The measurement of the peak currents is complicated by the effect of the electric double-layer charg- 


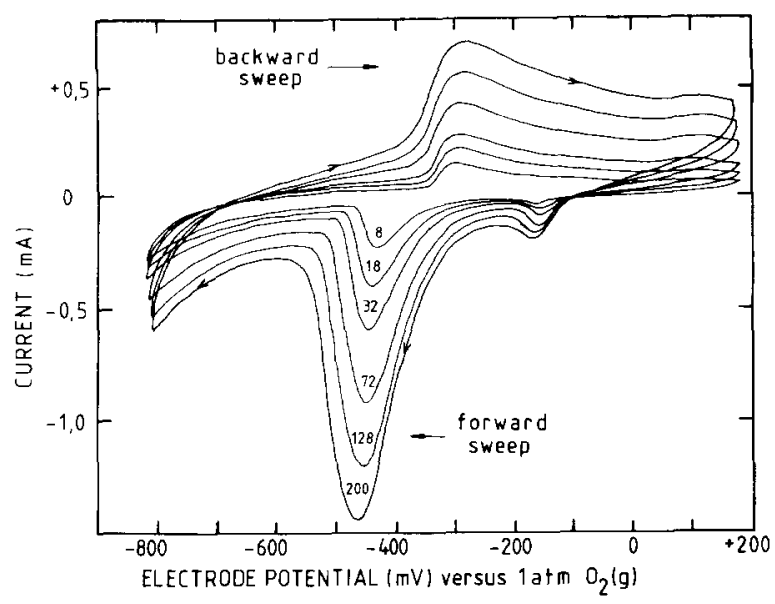

Fig. 2. Influence of the sweep rate on the cyclic voltammograms from the $\mathrm{Au}, \mathrm{N}_{2}(\mathrm{~g}) / \mathrm{Fe}$ implanted yttria-stabilized zirconia interface, measured at $877^{\circ} \mathrm{C}$ and $\left.P_{\mathrm{O}_{2}}=1.4 \pm 0.1\right) \times 10^{-6} \mathrm{~atm}$. The yttria-stabilized zirconia surface was implanted with $15 \mathrm{keV} \mathrm{Fe}$ up to a dose of $8 \times 10^{16}$ at $\mathrm{cm}^{-2}$. The sweep rate is indicated in $\mathrm{mV} / \mathrm{s}$.

ing. Since the electrode potential is continuously changing, a charging current, $I_{\mathrm{c}}$, flows:

$\left|I_{\mathrm{c}}\right|=A C_{\mathrm{d} 1} v$,

where $A$ is the electrode surface area, $C_{\mathrm{dl}}$ the capacitance of the electric double layer, and $v$ the sweep rate. The peak current must be measured from this baseline of the double layer charging current.

In this study the baseline due to the charging of the electric double layer could not be accurately determined. In order to estimate the error which can be made two values of the peak current were obtained: (1) measured with respect to the zero current baseline $\left(I_{\mathrm{f}, \mathrm{zcb}}\right)$, and (2) measured with respect to the estimated double layer charging current baseline $\left(I_{\mathrm{f}, \mathrm{dlcb}}\right) . I_{\mathrm{f}, \mathrm{zcb}}$ is equal to the sum $I_{\mathrm{f}, \mathrm{dlcb}}$ and the correction for the double layer charging, as indicated in fig. 3. This procedure was previously followed by Fabry and Kleitz [4].

Assuming semi-infinite linear diffusion of the oxidized species it can be derived [5] that the peak current is proportional to the square root of the sweep rate:

$I_{\mathrm{p}}=0.4463 n F A\left(\frac{n F}{R}\right)^{1 / 2}\left(\frac{D_{\mathrm{O}}}{T}\right)^{1 / 2} C_{\mathrm{O}} v^{1 / 2}$,

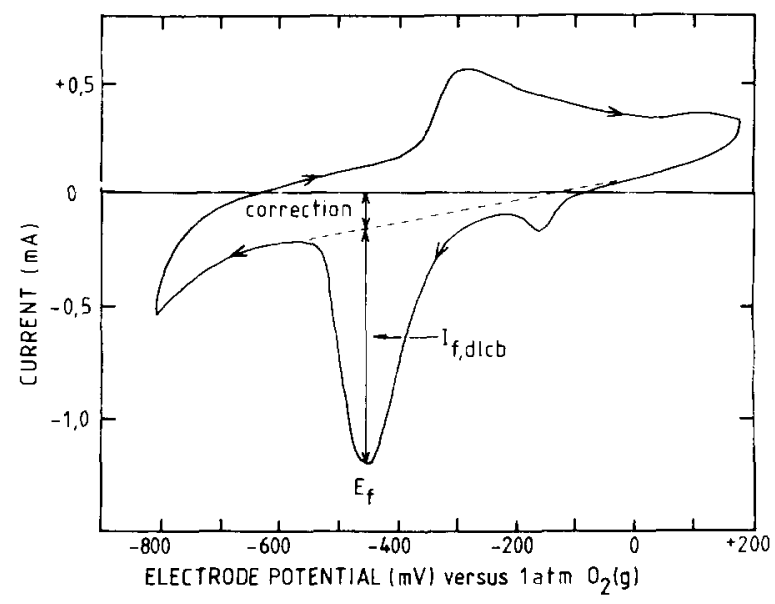

Fig. 3. Cyclic voltammogram for the $\mathrm{Au}, \mathrm{N}_{2}(\mathrm{~g}) / \mathrm{Fe}$ implanted yttria-stabilized zirconia interface, measured with a sweep rate of $128 \mathrm{mV} / \mathrm{s}$ at $877^{\circ} \mathrm{C}$ and $P_{\mathrm{O}_{2}}=(1.4 \pm 0.1) \times 10^{-6}$ atm. $I_{\mathrm{f}, \mathrm{zcb}}$ is equal to the sum of $I_{\mathrm{f} \text {,dcb }}$ and the correction for the double layer charging.

where $A$ is the electrode surface area $\left(\mathrm{m}^{2}\right), D_{\mathrm{O}}$ the diffusion coefficient of the oxidized species $\left(\mathrm{m}^{2} / \mathrm{s}\right)$ with an initial concentration $C_{\mathrm{O}}\left(\mathrm{mol} / \mathrm{m}^{3}\right), v$ the sweep rate $(\mathrm{V} / \mathrm{s}), n$ the number of electrons exchanged in the reaction, and $F$ and $R$ have their usual meaning. Eq. (2) can be simplified to:

$I_{\mathrm{p}}=K\left(\frac{D_{\mathrm{O}}}{T}\right)^{1 / 2} v^{1 / 2}$

or

$I_{\mathrm{p}}=\gamma v^{1 / 2}$,

where $K$ and $\gamma$ are proportionality constants. The measured peak current on the forward sweep curve is plotted as a function of the square root of the sweep rate in fig. 4. The peak current determined from the zero current baseline and from the estimated double layer charging current baseline obey the square root law given in eq. (4), but different values are obtained for the proportionality constant $\gamma$ (at $877^{\circ} \mathrm{C}$ : $\gamma\left(I_{\mathrm{f}, \mathrm{zbc}}\right)=(0.111 \pm 0.003) \mathrm{mA} /\left((\mathrm{mV} / \mathrm{s})^{0.5}\right)$, $\left.\left.\gamma\left(I_{\mathrm{f}, \mathrm{dlcb}}\right)=(0.096 \pm 0.003) \mathrm{mA} /(\mathrm{mV} / \mathrm{s})^{0.5}\right)\right)$.

The proportionality constant $\gamma$ contains the parameter $K$ and the diffusion coefficient $D_{\mathrm{O}}$. For the moment it is assumed that $K$ is independent of the temperature (see further discussion below). The activation energy of the diffusion coefficient can now 


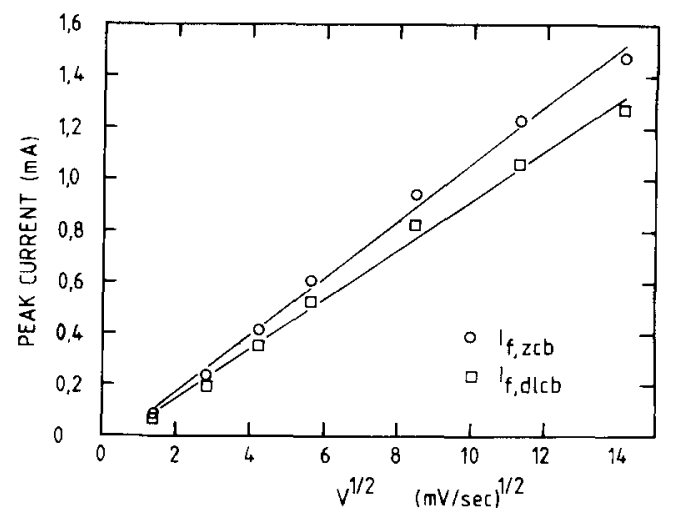

Fig. 4. Variation of the forward peak current as a function of the square root of the sweep rate, as determined from fig. 2 .

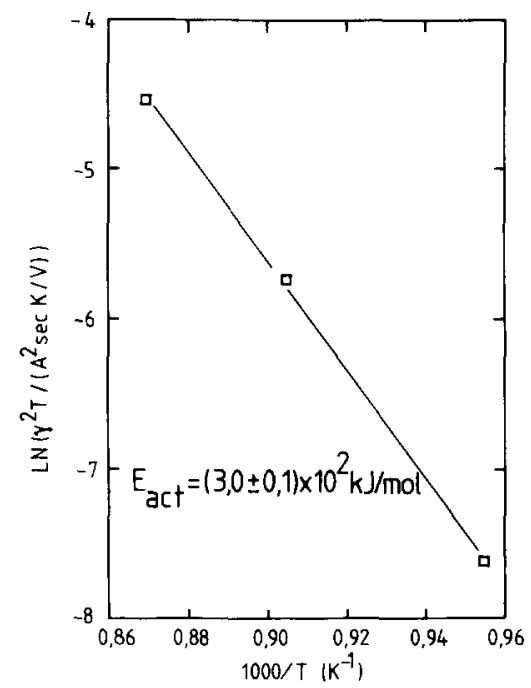

Fig. 5. Variation of the $\gamma^{2} T$ term of eq. (4) with temperature, as obtained from the corrected values of the peak current $\left(I_{\mathrm{f}, \mathrm{dlcb}}\right)$.

be obtained from the variation of $\gamma^{2} T$ with temperature, as shown in fig. 5. Activation energies are obtained of $E_{\text {act }}=(2.7 \pm 0.1) \times 10^{2} \mathrm{~kJ} / \mathrm{mol}$ and $E_{\text {act }}=(3.0 \pm 0.1) \times 10^{2} \mathrm{~kJ} / \mathrm{mol}$ depending on whether the peak current has been measured with respect to the zero current baseline or with respect to the estimated double layer charging current baseline.

The question can now be raised to the diffusion of active species to which this activation energy belongs. At least two active species can be considered, in the first place the iron cations themselves and secondly the electrons or electron holes in the im- planted surface layer. In order to discriminate between the two possibilities an estimate for the parameter $\gamma$ in eq. (4) is calculated. The necessary parameters for this calculation are the diffusion coefficient and the concentration of the electroactive species and these are presented below.

In a previous study the thermal stability of the $\mathrm{Fe}$ depth profiles in yttria-stabilized zirconia was determined $[2,9]$. From the time dependence of the $\mathrm{Fe}$ depth profile during annealing at elevated temperature values were obtained for the chemical diffusion coefficient of $\mathrm{Fe}^{3+}$ cations which varied from $6.3 \times 10^{-17} \mathrm{~cm}^{2} / \mathrm{s}$ at $800^{\circ} \mathrm{C}$ to $1.8 \times 10^{-15} \mathrm{~cm}^{2} / \mathrm{s}$ at $1000^{\circ} \mathrm{C}$. From the variation of the chemical diffusion coefficient of $\mathrm{Fe}$ with temperature an activation energy was obtained of $E_{\mathrm{act}}=(1.9 \pm 0.1) \times 10^{2} \mathrm{~kJ} /$ mol. Thus the activation energy of the chemical diffusion coefficient of $\mathrm{Fe}^{3+}$ in YSZ differs considerably from that of the diffusion coefficient of the electroactive species in the voltammogram.

The peak current in the voltammogram is also determined by the concentration of the oxidized species at the electrode. In the present case $50 \%$ of all cations at the surface is replaced by Fe in the ion implantation process, which results in an $\mathrm{Fe}$ concentration of $1.47 \times 10^{22}$ at $\mathrm{cm}^{-3}$.

The diffusion coefficients of electrons $\left(D_{\mathrm{e}}\right)$ and electron holes $\left(D_{\mathrm{h}}\right)$ in yttria-stabilized zirconia have been determined by Park [6]:

$D_{\mathrm{h}}=0.231 \exp [-(111 \mathrm{~kJ} / \mathrm{mol}) / R T]$

and

$D_{\mathrm{e}}=213.8 \exp [-(192 \mathrm{~kJ} / \mathrm{mol}) / R T]$.

At $800^{\circ} \mathrm{C}$ this results in a diffusion coefficient of $D_{\mathrm{e}}=1 \times 10^{-7} \mathrm{~cm}^{2} / \mathrm{s}$ and $D_{\mathrm{h}}=9 \times 10^{-7} \mathrm{~cm}^{2} / \mathrm{s}$. The diffusion coefficients of the electrons and electron holes are ten orders of magnitude higher than the diffusion coefficient of $\mathrm{Fe}^{3+}$ in the YSZ matrix. The activation energy of the diffusion coefficient of the electrons or electron holes is, however, still different from that found from the diffusion coefficient of the electroactive species in the cyclic voltammogram.

The concentration of the electrons or electron holes in YSZ is much lower than the Fe concentration and is given by: 
$n=1.04 \times 10^{32} \exp [-(192 \mathrm{~kJ} / \mathrm{mol}) / R T] P_{\mathrm{O}_{2}}^{-1 / 4}$

and

$p=1.72 \times 10^{21} \exp [-(60 \mathrm{~kJ} / \mathrm{mol}) / R T] P_{\mathrm{O}_{2}}^{+1 / 4}$.

At $800^{\circ} \mathrm{C}$ and $P_{\mathrm{O}_{2}}=10^{-6}$ atm this results in a hole concentration of $7 \times 10^{16}$ at cm $\mathrm{cm}^{-3}$.

From the data presented above it can now be calculated that the value of this parameter $\gamma$ for hole diffusion is about four orders of magnitude higher than for the diffusion of the Fe cations. Assuming that the electroactive species with the largest value for $\gamma$ determines the peak current in the voltammogram then it is learned from this analysis that the rate of the redox process at the $\mathrm{Au}, \mathrm{N}_{2}(\mathrm{~g}) / \mathrm{Fe}$ implanted yttria-stabilized zirconia interface is most likely determined by the diffusion of electron holes from the $\mathrm{Fe}^{3+}$ ions towards the gold electrode, where the electron holes are annihilated:

$\mathrm{Fe}^{3+} \rightarrow \mathrm{Fe}^{3+}+\mathrm{h}^{\cdot}$,

$\mathrm{e}^{-}+\mathrm{h}^{\circ} \rightarrow 0$.

The diffusion of the cations themselves to the electrode would result in much lower peak currents. A similar conclusion can be drawn if the diffusion of $\mathrm{Fe}$ cations, electrons or electron holes in the $\mathrm{Fe}_{2} \mathrm{O}_{3}$ lattice is considered.

A large discrepancy still exists between the activation energy of the diffusion coefficient of the active species as determined by cyclic voltammetry $\left(E_{\text {act }}=(3.0 \pm 0.1) \times 10^{2} \mathrm{~kJ} / \mathrm{mol}\right)$ and the activation energy of the diffusion coefficients of electrons $\left(E_{\text {act }}=192 \mathrm{~kJ} / \mathrm{mol}\right)$ or electron holes $\left(E_{\text {act }}=111 \mathrm{~kJ} /\right.$ $\mathrm{mol}$ ) in YSZ. Part of this discrepancy results from the fact that it was assumed that the concentration of active species was independent of the temperature. This no longer holds when electrons or electron holes are the active species as shown by the eqs. (7) and (8). The exponential temperature dependence of the electron hole concentration introduces an extra energy term in $K$ which increases the total (measured) activation energy.

Fabry and Kleitz [4] and Olmer et al. [7], studying the reduction of $\mathrm{Cu}$ and $\mathrm{Ce}$ point defects in YSZ, concluded also that the peak currents result from the diffusion of electrons or electron holes towards the $\mathrm{Cu}$ or $\mathrm{Ce}$ point defects. These authors focused their attention on the low values of diffusion coefficients of the cations in YSZ and on the large difference between the activation energies of the diffusion coefficient of the active species in the cyclic voltammetric experiment and the activation energies of the chemical diffusion coefficients of $\mathrm{Cu}$ and $\mathrm{Ce}$ in YSZ $\left(4<E_{\text {act }}<6 \mathrm{eV}\right)$. From the cyclic voltammetric experiments activation energies for the parameter $D_{\mathrm{O}}$ were obtained of $E_{\text {act }}=(158 \pm 5) \mathrm{kJ} / \mathrm{mol}$ and $E_{\text {act }}=(96 \pm 2) \mathrm{kJ} / \mathrm{mol}$ for $\mathrm{Cu}$ and Ce doped $\mathrm{YSZ}$, respectively. Those activation energies are low values in comparison to the activation energy of $D_{\mathrm{O}}$ as determined in our study of $\mathrm{Fe}$ implanted YSZ $E_{\text {act }}=(3.0 \pm 0.1) \times 10^{2} \mathrm{~kJ} / \mathrm{mol}$.

\subsubsection{Peak potential}

Fig. 2 shows a small shift of the reduction peak towards more negative potentials when the sweep rate and hence the peak current is increased. Part of this shift is due to the $I_{\mathrm{p}} R_{\mathrm{u}}$ drop between the working and reference electrodes. The correct values of the peak potential are shown in fig. 6 as a function of the logarithm of the sweep rate.

For a reversible reaction that the peak potential is independent of the scan rate [5]. For an irreversible system, where the electron transfer is slow, the peak potential is logarithmically dependent on the scan rate. As shown in fig. 4 , the peak potential is only

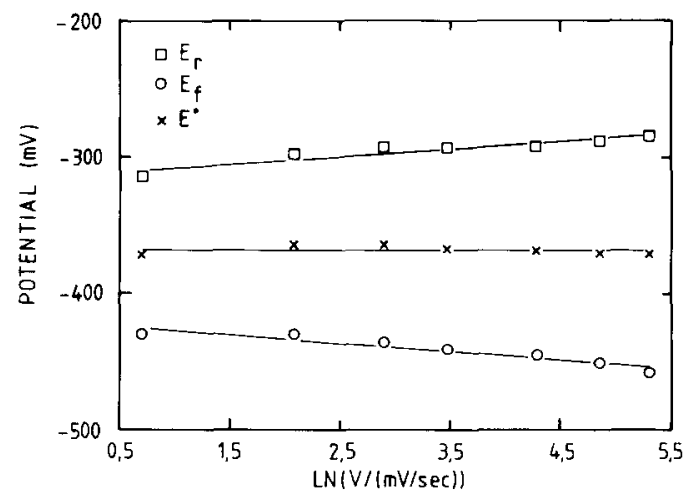

Fig. 6. Variation of the peak potentials as a function of the logarithm of the sweep rate, after correction for the $I R_{\mathrm{u}}$ potential drop between the working and reference electrode. $E^{0}$ represents the experimentally determined redox potential. The peak potential of the forward sweep $\left(E_{\mathrm{f}}\right)$ and the peak potential of the reverse sweep $\left(E_{\mathrm{R}}\right)$ were obtained from the voltammograms of fig. 2 . The redox potential $\left(E^{0}\right)$ followed from eq. (11). 
slightly dependent on the scan rate, which points to a reversible reaction at the electrode. At lower temperatures the peak potential become more dependent on the scan rate.

From voltammetry theory [5], the difference between the forward $\left(E_{\mathrm{F}}\right)$ and reverse peak $\left(E_{\mathrm{R}}\right)$ potential for a reversible reaction is given by:

$\Delta E_{\mathrm{p}}=2.18 \frac{R T}{n F}$,

where $n$ is the number of electrons exchanged in the redox reaction. From the potential difference between the forward and reverse peak potentials in fig. 6 values for $n$ are obtained in the range $0.5<n<0.8$. This suggests that a single electron is transferred in the redox reaction.

The redox potential, $E^{0}$, can be calculated from the following equation:

$E^{0}=\frac{\left(E_{\mathrm{F}}+E_{\mathrm{R}}\right)}{2}-\frac{1}{2} \frac{R T}{n F} \ln \left(\frac{D_{\mathrm{O}}}{D_{\mathrm{R}}}\right)$,

where $D_{\mathrm{O}}$ and $D_{\mathrm{R}}$ are the diffusion coefficients of the oxidized and reduced electroactive defects, respectively. But since only one electroactive species is involved (electrons or electron holes rather than $\mathrm{Fe}^{2+}$ or $\mathrm{Fe}^{3+}$ ions) it follows that $D_{\mathrm{O}} / D_{\mathrm{R}}=1$. The variation of $E^{0}$ with temperature is shown in fig. 7, in comparison with the coexistence electrode potentials of different mixtures of iron metal and iron oxides [8]. From this figure it can be concluded that the $E^{0}$

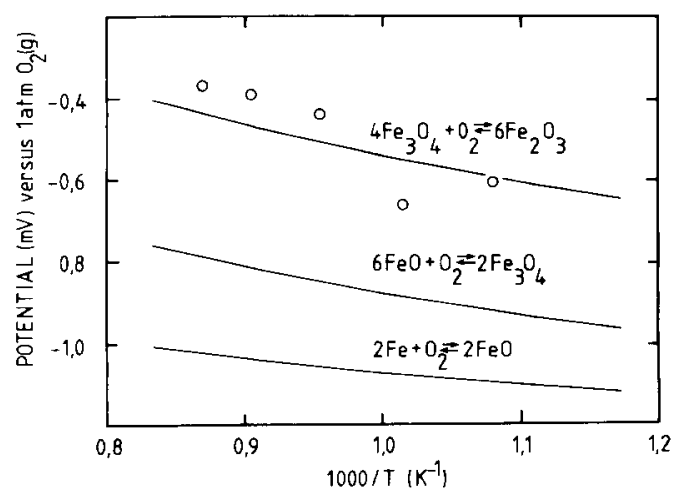

Fig. 7. Thermodynamic coexistence electrode potentials of different mixtures of iron and iron oxides [7] as a function of the temperature (drawn line) in comparison with the redox potential $E^{0}$ as determined by cyclic voltammetry (open circle). values as determined by cyclic voltammetry correspond to the thermodynamic potential of coexistent $\mathrm{Fe}_{2} \mathrm{O}_{3}$ and $\mathrm{Fe}_{3} \mathrm{O}_{4}$ phases:

$6 \mathrm{Fe}_{2} \mathrm{O}_{3} \rightleftarrows 4 \mathrm{Fe}_{3} \mathrm{O}_{4}+\mathrm{O}_{2}(\mathrm{~g})$.

Thus during the forward sweep in the cyclic voltammogram $\mathrm{Fe}$ ions are reduced from the $\mathrm{Fe}^{3+}$ to the $\mathrm{Fe}^{2+}$ oxidation state, in agreement with a one electron process.

Due to the reduction of $\mathrm{Fe}_{2} \mathrm{O}_{3}$ to $\mathrm{Fe}_{3} \mathrm{O}_{4}$, electrons become available in the solid electrolyte surface. This will result in an increase of the electronic conductivity in the surface of the solid electrolyte at low oxygen partial pressures or at large cathodic overpotentials. This redox reaction is also responsible for an increase of the double layer capacitance at the $\mathrm{Au}$, $\mathrm{O}_{2}(\mathrm{~g}) / \mathrm{YSZ}$ interface after $\mathrm{Fe}$ implantation, as was experimentally observed [1,9]. The implanted $\mathrm{Fe}$ ions provide in this way an additional mechanism for charge accumulation at that interface.

\section{Conclusions}

Cyclic voltammetry can be applied to study the oxidation state of implanted iron ions in yttria-stabilized zirconia. The peak current is proportional to the square root of the sweep rate which is representative for an electrode process limited by diffusion. Comparing the order of magnitude of the diffusion coefficients of the implanted $\mathrm{Fe}$ ions and the electrons or electron holes in YSZ it can be concluded that the peak currents result from the diffusion of electrons or electron holes to the implanted iron ions. An activation energy for the diffusion coefficient of the electroactive species of $E_{\text {acl }}=(3.0 \pm 0.1) \times 10^{2} \mathrm{~kJ} / \mathrm{mol}$ is obtained. This is a large value in comparison with cyclic voltammetric studies of yttria-stabilized zirconia doped with $\mathrm{Cu}$ $\left(E_{\mathrm{act}}=158 \pm 5 \mathrm{~kJ} / \mathrm{mol}\right)$ or Ce $\left(E_{\mathrm{act}}=96 \pm 2 \mathrm{~kJ} / \mathrm{mol}\right)$.

The observed redox potential corresponds to the thermodynamic potential of coexistent $\mathrm{Fe}_{3} \mathrm{O}_{4}$ and $\mathrm{Fe}_{2} \mathrm{O}_{3}$ phases. Hence during the forward sweep in the voltammogram, defined for negatively swept potentials, part of the $\mathrm{Fe}^{3+}$ cations is reduced towards $\mathrm{Fe}^{2+}$. This redox reaction will result in an increase of the electronic conductivity of the surface of the solid electrolyte and is held responsible for an in- 
crease of the double layer capacitance at the Au, $\mathrm{O}_{2}(\mathrm{~g}) / \mathrm{YSZ}$ interface after Fe implantation.

\section{Acknowledgement}

The authors appreciate the cooperation with the Laboratorium voor Algemene Natuurkunde (LAN) of the State University of Groningen. They are grateful to J.J. Smit for the ion implanter facilities. The investigations were supported by the Netherlands Foundation for Chemical Research (SON) with financial aid from the Netherlands Organisation for Scientific Research (NWO).

\section{References}

[1] B.A. van Hassel and A.J. Burggraaf, Solid State Ionics 48 (1991) 139.
[2] B.A. van Hassel and A.J. Burggraaf, Appl. Phys. A. 53 (1991) 155.

[3] B.A. van Hassel and A.J. Burggraaf, Appl. Phys. A 52 (1991) 410.

[4] P. Fabry and M. Kleitz, J. Electrochem. Soc. 126 (1979) 2183.

[5] A.J. Bard and L.R. Faulkner, Electrochemical Methods: Fundamentals and Applications (Wiley, New York, 1980).

[6] Jong-Hee Park, Electronic transport in yttria stabilized zirconia, $\mathrm{Ph}$. D thesis (Marquette University, Milwaukee, WI 1985).

[7] L.J. Omer, J.C. Viguie, E.J.L. Schouler, Solid State Ionics 7 (1982) 23

[8] I. Barin and O. Knacke, Thermochemical properties of inorganic substances (Springer, Berlin, 1973).

[9] B.A. van Hassel, Transport and oxygen transfer properties of ion implanted yttria stabilized zirconia, $\mathrm{PhD}$ Thesis (University of Twente, Enschede, The Netherlands, 1990). 